\title{
Evaluation of the performance of the modified early warning score in a Brazilian public hospital
}

\author{
Avaliação do desempenho do escore de alerta precoce modificado em hospital público brasileiro \\ Evaluación del desempeño de la puntuación de alerta temprana modificada en un hospital público brasileño
}

Universidade de São Paulo. Ribeirão Preto, São Paulo, Brasil.

How to cite this article:

Montenegro SMSL, Miranda CH. Evaluation of the

performance of the modified early warning score in a Brazilian public hospital. Rev Bras Enferm. 2019;72(6):1428-34. doi: http://dx.doi.org/10.1590/0034-7167-2017-0537

Corresponding Author:

Sayane Marlla Silva Leite Montenegro E-mail: sayane_ufpb@hotmail.com

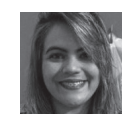

Submission: 09-07-2017 Approval: 11-22-2017

\section{ABSTRACT}

Objective: To evaluate the performance of the modified early warning score (Mews) in a nursing ward for patients in clinical deterioration. Method:This is an analytical, quantitative and predictive study. Mews' parameters (systolic blood pressure, heart rate, respiratory rate, temperature and level of consciousness) were evaluated every six hours. The following events were reported: death, cardiopulmonary arrest and transfer to intensive care. The evaluations were performed in a hospital of reference in the state of São Paulo, Brazil. Results: A total of 300 patients were included ( $57 \pm 18$ years old, males: $65 \%$ ). There number of combined events was observed to be greater the higher the score's value $(00 \% ; 00 \%$; $01 ; 09 \% ; 19 \% ; 28 \% ; 89 \%$, respectively, for Mews $0 ; 1 ; 2 ; 3 ; 4 ; 5$ and $6 ; p<0.0001)$. Mews $\geq$ 4 was the most appropriate cut-off point for prediction of these events (sensitivity: $87 \%$, specificity: $85 \%$ and accuracy: 0.86 ). Conclusion: Mews properly measured the occurrence of severe events in hospitalized patients of a Brazilian public hospital's nursing ward. Mews $\geq 4$ seems to be the most appropriate cut-off point for prediction of these events.

Descriptors: Organ Dysfunction Scores; Emergency Medicine; Nursing Care; Critical Care; Rapid Response Teams in Hospitals.

\section{RESUMO}

Objetivo: Avaliar o desempenho do escore de alerta precoce modificado (Mews) em uma enfermaria de pacientes em deterioração clínica. Método: Trata-se de um estudo analítico, quantitativo e preditivo. Os parâmetros do Mews (pressão arterial sistólica, frequência cardíaca, frequência respiratória, temperatura e nível de consciência) foram avaliados de 6 em 6 horas. Os seguintes eventos foram registrados: óbito, parada cardiorrespiratória e transferência para terapia intensiva. As avaliações foram realizadas em um hospital de referência do interior do estado de São Paulo. Resultados: Foram incluídos 300 pacientes (57 \pm 18 anos, sexo masculino: $65 \%)$. Observou-se número crescente de eventos combinados de acordo com o maior valor do escore $(00 \% ; 00 \% ; 01 \%$; $09 \%$; $19 \%$; $28 \% ; 89 \%$, respectivamente, para os Mews $0 ; 1 ; 2 ; 3 ; 4 ; 5$ e $6 ; p<0,0001)$. Mews $\geq 4$ foi o ponto de corte mais adequado para predição destes eventos (sensibilidade: $87 \%$, especificidade: $85 \%$ e acurácia: 0,86). Conclusão: Mews mensura adequadamente a ocorrência de eventos graves em pacientes hospitalizados em enfermaria de um hospital público brasileiro. Mews $\geq 4$ parece ser o ponto de corte mais adequado para predição destes eventos.

Descritores: Escores de Disfunção Orgânica; Medicina de Emergência; Cuidados de Enfermagem; Cuidados Críticos; Equipes de Resposta Rápida de Hospitais.

\section{RESUMEN}

Objetivo: Evaluar el desempeño de la puntuación de alerta temprana modificada (Mews) en una enfermería de pacientes con deterioro clínico. Método: Se trata de un estudio analítico, cuantitativo y predictivo. Los parámetros Mews (presión arterial sistólica, frecuencia cardíaca, frecuencia respiratoria, temperatura y nivel de conciencia) se evaluaron cada 6 horas. Se registraron los siguientes eventos: muerte, parada cardiorrespiratoria y transferencia para la terapia intensiva. Las evaluaciones se realizaron en un hospital de referencia del interior del estado de São Paulo. Resultados: Participaron 300 pacientes ( $57 \pm 18$ años; sexo masculino: $65 \%)$. Se observó un número creciente de eventos asociados según el mayor valor de la puntuación (00\%; 00\%; 01\%; 09\%; 19\%; 28\%; 89\%, respectivamente, para los Mews 0; $1 ; 2 ; 3$; $4 ; 5$ y $6 ; p<0,0001)$. Los Mews $\geq 4$ fueron el punto de corte más adecuado para la predicción de estos eventos (sensibilidad: 87\%; especificidad: 85\%; y exactitud: 0,86). Conclusión: Los Mews permitieron estimar adecuadamente la ocurrencia de eventos graves en pacientes hospitalizados en la enfermería de un hospital público brasileño. Los Mews $\geq 4$ parece ser el punto de corte más adecuado para predecirlos.

Descriptores: Puntuaciones de Disfunción de Órganos; Medicina de Emergencia; Atención de Enfermería; Cuidados Críticos; Personal de Respuesta Rápida de Hospitales. 


\section{INTRODUCTION}

The acute clinical deterioration of patients is preceded by the change of their vital parameters ${ }^{(1-2)}$. This clinical worsening is generally recognized belatedly in nursing wards, which can lead to an increase in these patients' morbidity and mortality ${ }^{(3-4)}$. Acute deterioration can be recognized early with the measurement and interpretation of vital parameters, allowing a rapid intervention to stop the patient's clinical worsening and preventing the occurrence of severe events such as death or cardiopulmonary arrest.

The rapid response teams were created to carry out speedy interventions in patients with clinical deterioration, the first having been described by Lee et al. in $1995^{(5)}$. However, for the proper operation of this system, it is required that it is adequately triggered, mainly by the nursing staff.

To properly identify patients with clinical deterioration in the nursing ward as early as possible, several scores which integrate different parameters emerged, such as the Early Warning Score EWS and its modified version (Mews). These scores are based on the evaluation of physiological parameters that can be easily obtained at the patient's bedside ${ }^{(1-2)}$. They are assigned in accordance with the anomalies found to measure the patient's risk of clinical deterioration, as shown in Table $1^{(6-7)}$.

There are several international investigations for validation of these scores with this purpose. However, in our country, various institutions, mainly private ones, employ these scores in the nursing wards of their hospitals without adapting them to this scenario. These scores need to be validated to ensure their high specificity and sensitivity ${ }^{(3)}$. The objective of this investigation was to assess whether the modified early warning score (Mews) properly measures the risk of severe events such as death and cardiopulmonary arrest in a Brazilian public hospital's nursing ward, and to determine the best cut-off point for triggering the rapid response team in this scenario.

\section{OBJECTIVE}

To evaluate the clinical impact of the modified early warning score (Mews) in association with a rapid response team to reduce the number of severe adverse events in the nursing wards of an emergency hospital.

To assess the occurrence of events such as: unexpected death, cardiopulmonary arrest and transfers to monitored beds before and after the deployment of Mews.

\section{METHOD}

\section{Ethical aspects}

This is an analytical and quantitative study for validation of the modified early warning score (Mews) in the identification of severe events, like unexpected death, cardiopulmonary arrest and transfer to the intensive care unit (ICU).

\section{Study design and location}

This study was conducted in the general outpatient nursing ward of the Emergency Unit of Hospital das Clínicas, belonging to the University of São Paulo's School of Medicine of Ribeirão Preto. This unit is a nursing ward of a hospital that is dedicated exclusively to the care of highly complex emergencies within the Unified Health
System (SUS). The choice for the realization of this study in this unit was based on its high prevalence of severe events, such as death and cardiopulmonary arrest, mostly due to the peculiarities and complexity of the patients admitted.

\section{Population and sample}

Patients over the age of 18 years old, of both sexes, with any primary diagnosis, hospitalized in the unit for at least 24 hours during the period from June 16 to December 22, 2016, were included in this study. The patients were included only after they or their legal guardian had agreed to participate in the study and signed the informed consent form. All patients hospitalized in this unit receiving palliative care were excluded, this classification having been carried out by a team that was specialized in this kind of care, and there was no involvement of the researchers in this decision. The study was approved by the Research Ethics Committee of Hospital das Clínicas, belonging to the University of São Paulo's School of Medicine of Ribeirão Preto.

\section{Data collection}

Data on the following vital signs were collected: systolic blood pressure in $\mathrm{Hg} \mathrm{mm}$, heart rate in beats per minute, respiratory rate in incursions per minute, and temperature in Celsius degrees. These parameters were evaluated routinely by this unit's nursing staff every 6 hours. These vital signs were included by the nursing professionals in each patient's electronic health record via manual typing.

To carry out this investigation, the simplified assessment of consciousness level, as shown in Table 1, was incorporated into the monitoring of the vital signs present in this unit's electronic health record. All members of the unit's nursing staff were trained for the standardization of the assessment of consciousness level and of each vital sign that was part of this score. An algorithm similar to that shown in Table 1 was incorporated in the electronic health record, and after insertion of the vital signs evaluated by the nursing staff, the Mews value was automatically generated.

Table 1 - Modified Early Warning Score, Ribeirão Preto, São Paulo, Brazil, 2016

\begin{tabular}{lccccccc}
\hline & $\mathbf{7}$ & \multicolumn{7}{c}{ Scores } \\
& $\mathbf{3}$ & $\mathbf{2}$ & $\mathbf{1}$ & $\mathbf{0}$ & $\mathbf{1}$ & $\mathbf{2}$ & $\mathbf{3}$ \\
\hline HR & - & $\leq 40$ & $41-50$ & $51-100$ & $101-110$ & $111-129$ & $\geq 130$ \\
RR & - & $\leq 8$ & $9-12$ & $13-20$ & $21-25$ & $26-29$ & $\geq 30$ \\
SBP & $\leq 70$ & $71-80$ & $81-99$ & $100-140$ & $141-160$ & $161-199$ & $\geq 200$ \\
T & $\leq 35$ & $35.1-36.0$ & $36.1-37.7$ & $37.8-38.9$ & $\geq 39$ & \\
LC & & & A & $C$ & RD & I \\
\hline
\end{tabular}

Source: Adapted from Prytherch et al., 2010, p. 934(8).

Notes: Heart rate (HR), respiratory rate (RR), systolic blood pressure (SBP), temperature $(T)$, level of consciousness (LC).

The researcher had access to all these parameters and recorded the whole evolution of the Mews values observed during the patient's period of hospitalization in the unit. In this validation phase, the Mews value found did not lead to any interventions or differentiated assessments. The choice to request additional medical evaluation for the patients hospitalized in this unit was at the discretion of the nurse in charge, according to his/her personal experience.

The occurrence of severe events during hospitalization was evaluated prospectively, considering the following outcomes: death by any cause observed in the nursing ward, cardiopulmonary arrest in different heart rhythms documented by the medical team responsible for the assessment 
of patients in the ward, and transfer to monitored beds, including the patient's transferring to a more specialized health care unit such as the intensive care unit, the coronary care unit or the semi-intensive care unit. These outcomes were analyzed in combination and in isolation.

\section{Statistical analysis}

The categorical variables were described in percentage. The continuous variables with normal distribution were expressed as mean and standard deviation, and those without normal distribution were expressed as median and 25 and 75 percentiles. The Shapiro-Wilk test was used to evaluate the type of distribution. For comparison between different categorical variables, the Chi-square test was used. For comparison between three or more variables with non-normal distribution, the Kruskal-Wallis test was used along with Dunn's post-test. For each Mews cut-off value, sensitivity, specificity, positive predictive value, negative predictive value, likelihood and area under the ROC (receiver operating characteristic curve) (AUC) were calculated. Statistical significance was considered to be a two-tailed $\mathrm{p}$-value lower than 0.05. Data analysis and the construction of the graphs were performed using the Stata statistical software version 13.1 (College Station, TX, USA).

\section{RESULTS}

In the data collection period (June 16 to 22 December 2016), 380 patients were hospitalized in the medical clinic of HC-FMRP-USP's Emergency Unit. The sample of this study consists of three-hundred patients, eighty of which were excluded for the following reasons: twelve patients had been used in the pilot study conducted by the investigators, 48 patients due to a strictly palliative nursing diagnosis, and twenty patients or caregivers who did not accept to participate in the study.

The included patients' demographic and clinical characteristics are shown in Table 2 . The mean age of the patients was $57 \pm 18$ years old, with predominance of males (65\%). The clinical diagnoses were varied, as was the presence of several associated comorbidities, which was expected due to the study having been developed in the general nursing ward of a tertiary emergency hospital.

In relation to these patients' hospitalization, the median length was $06(03 ; 11)$ days, and hospital mortality was $16 \%(48 / 300)$. A total of 1,240 Mews value assessments were analyzed, with 32 evaluations per patient on average.

As for the distribution of the highest Mews value encountered during hospitalization, the following prevalence was noted, in decreasing order: Mews 2 (25\%), Mews 3 (22\%), Mews 1 (20\%), Mews 6 (15\%), Mews 5 (08\%) and Mews 0 and 4 (both with 05\%).

To analyze the occurrence of the events according to Mews value, as shown in Figure 1, a progressive increase of combined events was observed, with low incidence of events in scores 0,1 and $2(0.6 \%)$, an intermediary number of events in score $3(09 \%)$, and a high prevalence of events in scores 4 (19\%), 5 (28\%) and 6 (89\%), $p<0.001$. A similar distribution is observed by separately analyzing the events of unexpected death, cardiopulmonary arrest and transfer to the ICU, also with statistical significance, $\mathrm{p}<0.0001$.

In relation to Mews' temporal evolution before it reaches its highest value, shown in Figure 2, there is no significant difference of this score compared to that of 6 hours before, $p>0.9$; however, there is significant difference in the 24,18 and 12 hours preceding it, $\mathrm{p}<$
0.0001 , showing that usually, the patient experiences a progressive elevation of the Mews value before it peaks.

In relation to the most suitable cut-off point for prediction of the occurrence of combined severe events (unexpected death, cardiopulmonary

Table 2 - Demographic and clinical characteristics of the patients included in the study, Ribeirão Preto, São Paulo, Brazil, 2016

\begin{tabular}{lc}
\hline Characteristic & $\mathbf{N}=\mathbf{3 0 0}$ patients \\
\hline Demographic & \\
Age (years), mean $\pm \mathrm{sd}$ & $57 \pm 18$ \\
Male gender, $\mathrm{n}(\%)$ & $194(65)$ \\
Main Diagnosis & \\
Any infection, $\mathrm{n}(\%)$ & $123(41)$ \\
Sepsis, $\mathrm{n}(\%)$ & $28(09)$ \\
Renal insufficiency, $\mathrm{n}(\%)$ & $17(06)$ \\
Exogenic poisoning, $\mathrm{n}(\%)$ & $9(03)$ \\
COPD acute exacerbation, $\mathrm{n}(\%)$ & $7(02)$ \\
Psychiatric disorder, $\mathrm{n}(\%)$ & $8(03)$ \\
Acute myocardial infarction, $\mathrm{n}(\%)$ & $35(12)$ \\
Cardiorespiratory arrest & $5(02)$ \\
Gastrointestinal bleeding, $\mathrm{n}(\%)$ & $19(06)$ \\
Liver cirrhosis, $\mathrm{n}(\%)$ & $17(06)$ \\
Fluid and electrolyte disorder, $\mathrm{n}(\%)$ & $2(01)$ \\
Circulatory shock & $7(02)$ \\
Comorbidities & \\
Arterial hypertension, $\mathrm{n}(\%)$ & $89(30)$ \\
Diabetes mellitus, $\mathrm{n}(\%)$ & $44(15)$ \\
Neoplasia, $\mathrm{n}(\%)$ & $5(02)$ \\
Heart diseases, $\mathrm{n}(\%)$ & $48(16)$ \\
Sequela, $\mathrm{n}(\%)$ & $32(11)$ \\
COPD, $\mathrm{n}(\%)$ & $8(03)$ \\
HIV, $\mathrm{n}(\%)$ & $21(07)$ \\
None, $\mathrm{n}$ (\%) & $15(05)$ \\
Hospitalization & \\
Duration (days), median (percentiles) & $6(3 ; 11)$ \\
Intra-hospital mortality, $\mathrm{n}(\%)$ & $48(16)$ \\
Highest Mews distribution & \\
0, $\mathrm{n}(\%)$ & $16(05)$ \\
, n $(\%)$ & $60(20)$ \\
$2, \mathrm{n}(\%)$ & $74(25)$ \\
$3, \mathrm{n}(\%)$ & $65(22)$ \\
$4, \mathrm{n}(\%)$ & $16(05)$ \\
$5, \mathrm{n}(\%)$ & $25(08)$ \\
$6, \mathrm{n}(\%)$ & $44(15)$ \\
\hline
\end{tabular}

Source: HCFMRP, 2016.

Notes: Chronic obstructive pulmonary disease (COPD), human immunodeficiency virus (HIV), modified early warning score (Mews).

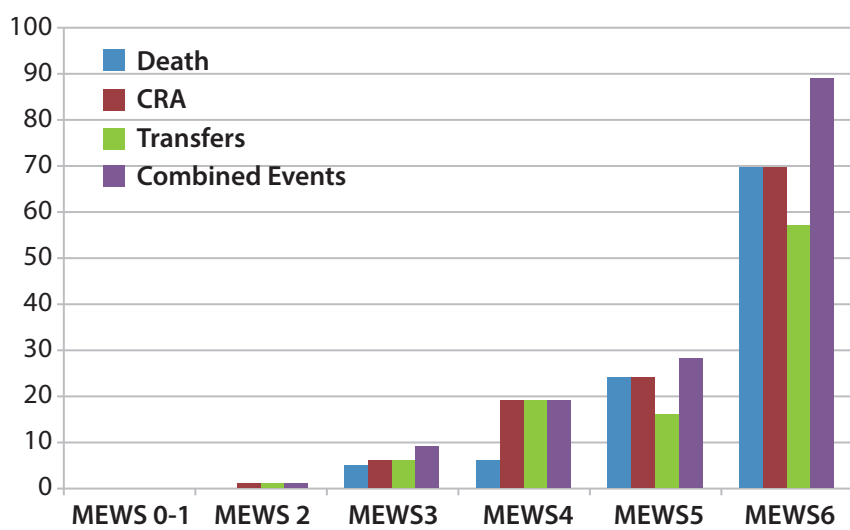

Source: HCFMRP, 2016.

Figure 1 - Number of events observed during hospitalization according to the modified early warning score, Ribeirão Preto, São Paulo, Brazil, 2016

arrest and transfer to the ICU), as shown in Figure 3, there is reduced accuracy for Mews $\geq 1$ and 2, with 0.52 (95\% confidence interval $[\mathrm{Cl}]$ : 
$0.51-0.55)$ and 0.65 (95\% Cl: $0.62-0.68)$ AUC-ROC values, respectively, markedly due to their low specificity; intermediate accuracy is observed for Mews $\geq 3$, with a 0.79 (95\% Cl: $0.76-0.83)$ AUC-ROC, and high accuracy is observed for Mews $\geq 4$ with a 0.86 (95\% Cl: 0.81 - 0.91) AUC-ROC, but with no significant elevation of accuracy from this point on, as can be observed in relation to Mews $\geq 5$, with a similar 0.86 (95\% Cl: 0.80 - 0.91) AUC-ROC. As also noted in Figure 3 and Table 3, with regard to the sensitivity and the specificity of each cut-off point, Mews $\geq 4$ seems to be the most appropriate. It was observed that Mews $\geq 4$ had the most suitable parameters for the proposal of the rapid response team's triggering.

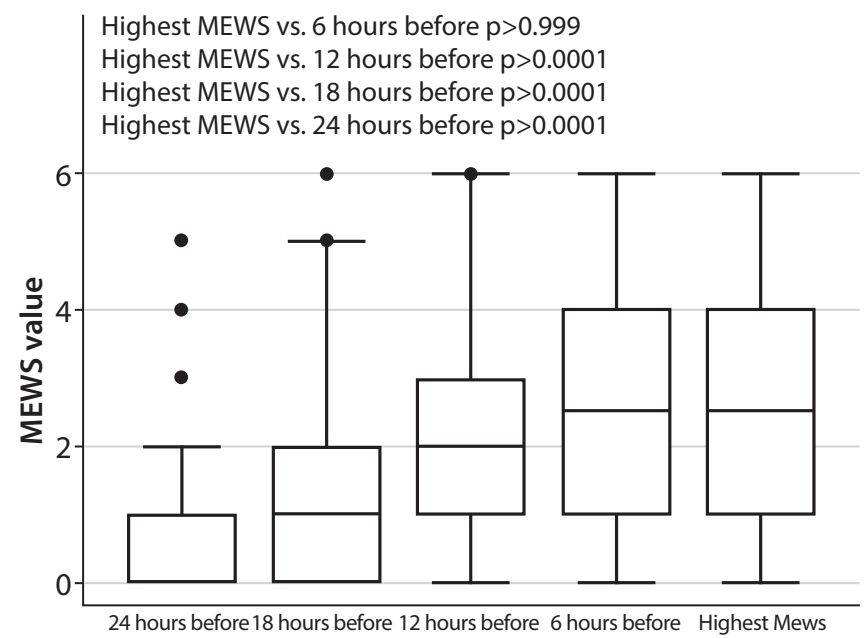

Source: HCFMRP, 2016

Figure 2 - Box-plot showing the time evolution of the modified early warning scores (Mews) 6, 12, 18 and 24 hours before it reaches its highest value observed during hospitalization, Ribeirão Preto, São Paulo, Brazil, 2016
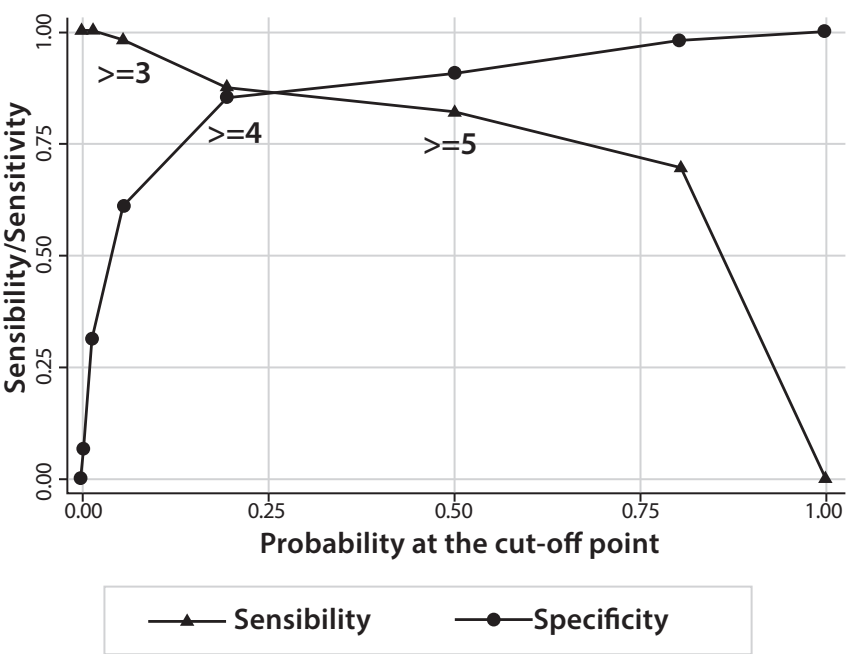

Source: HCFMRP, 2016.

Note: Receiver Operating Characteristic (ROC).

Figure 3 - Description of the sensitivity, specificity, positive predictive value, negative predictive value, likelihood ratio, percentage of correct classifications and AUC-ROC for identification of combined adverse events, in accordance with different Mews cut-off points, Ribeirão Preto, São Paulo, Brazil, 2016
By analyzing each parameter separately from Mews, the following frequency of each parameter was found in the total score: systolic blood pressure $(35 \%)$, heart rate $(55 \%)$, respiratory rate $(35 \%)$, temperature (33\%) and level of consciousness (41\%).

\section{DISCUSSION}

Mews is a versatile tool, easy to measure, based on physiological parameters, that is able to warn the nursing staff of the best time to trigger the rapid response team. Although it has been extensively validated in the global scientific literature for this purpose, no Brazilian study that we know of has validated the use of this score within its hospital units, despite its use being disseminated mainly in our country's private health institutions. In this sense, our research showed that the value of this score can properly quantify the number of significant severe events in patients hospitalized in a general nursing ward of a Brazilian public emergency hospital.

\section{Categorization of the risk of severe events by Mews}

Mews is a simple tool that allows assessing the risk of severe events such as unexpected deaths, cardiopulmonary arrest and transfers to intensive care beds. In this sense, our study showed that a Mews value greater than 4 and 5 had appropriate accuracy for identification of the risk of some of these serious events, with 0.86 (95\% Cl: $0.81 ; 0.91)$ and 0.86 (95\% Cl: 0.81; 0.91) AUC-ROC values, respectively.

Currently, in the scientific literature, there is a wide variety of early warning scores being used, but the four scores with the best AUC-ROC in relation to mortality and risk stratification obtained values between 0.78 and 0.72 , i.e., showed moderate discrimination ${ }^{(4)}$.

In comparison to 33 other warning scores, Mews showed good discrimination for combined outcomes (cardiac arrest, admission to the ICU or death in 24 hours), with a 0.87 AUC-ROC. In relation to the prediction of isolated events, it was noted that the AUC-ROC ranged between 0.88 and 0.93 for the prediction of death, and between 0.74 and 0.86 for the identification of cardiopulmonary arrest. Therefore, our investigation showed similar accuracy values in relation to what was observed in these other studies using the C-statistic of the ROC curves $^{(7)}$.

In a systematic review, it was noted that Mews' accuracy for the prediction of death obtained an AUC-ROC ranging from 0.88 to 0.93 , and between 0.74 and 0.86 for the prediction of cardiopulmonary arrest. These data are consistent with what was found in our investigation ${ }^{(9)}$.

In 2013, Ho et al. ${ }^{(10)}$ showed in a study with 267 patients that there had been 47 deaths (6.6\%) in patients with Mews $<4$ compared to 53 
deaths (17\%) in those with Mews $\geq 4$, corroborating the Mews value as being directly proportional to the occurrence of severe events such as death and cardiopulmonary arrest. This was also shown in our investigation, both in relation to the occurrence of combined events and to their analysis in isolation, as shown in Table 3 and Figure 2, the number of severe events observed having been higher the greater the value of this score.

The study by Wheeler et al. ${ }^{(11)}$ showed that Mews was conceived in hospitals of first world countries, and that applying it in places with scarcity of resources could thus reduce its accuracy. In their study, they showed that Mews $\geq 5$ had low sensitivity: $58.8 \%(95 \% \mathrm{Cl}: 44.2-72.4)$ and low specificity: $56.2 \%$ (95\% Cl: $49.8-62.4)$ for the identification of these severe events. This study emphasized the need for Mews'validation in each particular scenario. However, in our investigation, the maintenance of adequate accuracy, similar to that observed in studies conducted in developed countries, was observed by using this same cut-off point (Mews $\geq 5$ ), resulting in values such as $82 \%$ sensitivity ( $95 \% \mathrm{Cl}: 70-91$ ) and $91 \%$ specificity (95\% Cl: $86-$ 94) for the identification of severe events, for instance.

In an interesting research carried out in the emergency department, it was noted that Mews' sensitivity and specificity for detection of the patients' clinical deterioration was similar to that found for patients in monitored beds (sensitivity: $100 \%$ versus $100 \%$, specificity: $98.3 \%$ versus $97.8 \%)^{(12)}$. This fact is important for regions with limited resources, where there are often no monitored beds available for the hospitalization of patients in the emergency room.

In 2011, an observational study with one hundred adults admitted to the emergency resuscitation room of the medical and surgical nursing wards of a hospital of reference in Portugal was published, with the retrospective estimation of the Mews value 12, 24 and in 72 hours before admission to this unit, and it was concluded that, in the hours preceding these severe events, there is aggravation of the physiological parameters and consequent increase of this score ${ }^{(13)}$. As shown in our investigation, as can be seen in Figure 2, statistically significant difference was not observed only in the six hours preceding the highest Mews value, with progressive elevation of this score in relation to 12,18 and 24 hours before it peaked. Therefore, it is evidenced that generally, the clinical deterioration of vital parameters is progressive and its early identification can allow the realization of treatments to stop this progression.

\section{Determination of the best cut-off point}

There is still a lot of disagreement about the best cut-off point to trigger the rapid response teams due to the higher probability of severe events from this point on. In this sense, in our study, it seems that the best cut-off point was Mews $\geq 4$, with $87 \%$ sensitivity and $85 \%$ specificity, as can be observed in Figure 3. In 2014, Leandro ${ }^{(14)}$, in his studies with 439 patients for validation and translation of this score in Portugal, determined the best Mews cut-off point for the 24 hours, 48 hours and 72 hours preceding an event. In this sense, in the 24 hours before an event, the optimal cut-off point was 5.5 with $100 \%$ sensitivity and $92.3 \%$ specificity; in the 48 hours before this event, the most appropriate cut-off point was 4.5 with $80 \%$ sensitivity and $85.4 \%$ specificity, and in the 72 hours before it, this point was 4.5 with $66.7 \%$ sensitivity and $87.9 \%$ specificity.

\section{Variations of the parameters analyzed by Mews}

The parameters used in Mews' estimation, such as heart rate, oxygen saturation, breathing difficulties, increased need for oxygen supplementation, etc, greatly vary. Each study determined the vital signs that are possible to be verified according to the reality of each institution, which hinders the comparison of the results of different investigations. In our study, we used the following parameters: heart rate $(H R)$, respiratory rate $(\mathrm{RR})$, temperature $(\mathrm{T})$, systolic blood pressure (SBP) and simplified level of consciousness (LC). These parameters were chosen because they are easy to measure, highly reproducible, objective, quantitative in nature and have no need of additional technological resources such as the pulse oximeter, which facilitates their application in different health care units.

Our study also shows the need for integrated assessment of these five vital signs, with the following prevalence for each parameter: systolic blood pressure (35\%), heart rate (55\%), respiratory rate (35\%), temperature (33\%) and level of consciousness ( $41 \%)$, i.e., all parameters had high prevalence, justifying their incorporation and systematic evaluation.

\section{Determination of conduct flowcharts}

The data obtained in our research made it possible to define three risk layers that assisted in the creation of conduct flowcharts. The first layer corresponds to low risk of complications and of triggering of adverse events (Mews 0, 1 and 2), which would not justify any additional interventions, only the patient's follow-up and observation by the nursing staff; however, patients with progressive elevation of the score, even if within this range, should have their vital parameters evaluated more frequently. The intermediate risk layer (Mews 3) would justify the assessment of the vital signs more often by the nursing staff, as well as the request for medical assessment by the professional in charge of the patient's follow-up, who would have some time still to evaluate him/her. And finally, the high risk layer (Mews 4, 5 and 6) would justify the immediate triggering of the rapid response team if the physician responsible for the patient is not present at the scene. Figure 4 shows the suggestion of a flowchart integrating the Mews score with the triggered conducts.

In 2010, Albino et al. ${ }^{(15)}$ published a qualitative study in which they evaluated the warning score of 113 inpatients in the surgery services of Barlavento Algarvio's hospital center in the period from March to April 2009. They concluded that the implementation of this score in association with an intervention algorithm translates into improvement of the patients' clinical outcome, and also entails advantages for the health professionals, mainly related to the promotion of the communication between them. Interviews were made with the nurses and they all recognized the importance of the implementation of this score; moreover, all nurses trained in the use of Mews in our study recognized its relevance to improve the quality of health care and facilitate the communication with the medical team.

In 2010, by recommendation of the Department of Health Quality, it was suggested that all hospitals of the National Health System created and implemented one of these warning scores based on the following assumptions: an early and adequate intervention can decrease the morbidity and mortality of hospitalized patients undergoing acute clinical deterioration processes, and the implementation of organizational mechanisms that enable their rapid identification and the deployment of optimized and timely care practices is imperative ${ }^{(15)}$. It is known that the implementation of care practices should cover different areas of intervention, such as: criteria for triggering of the rapid response team, human resources training, immediate resuscitation 


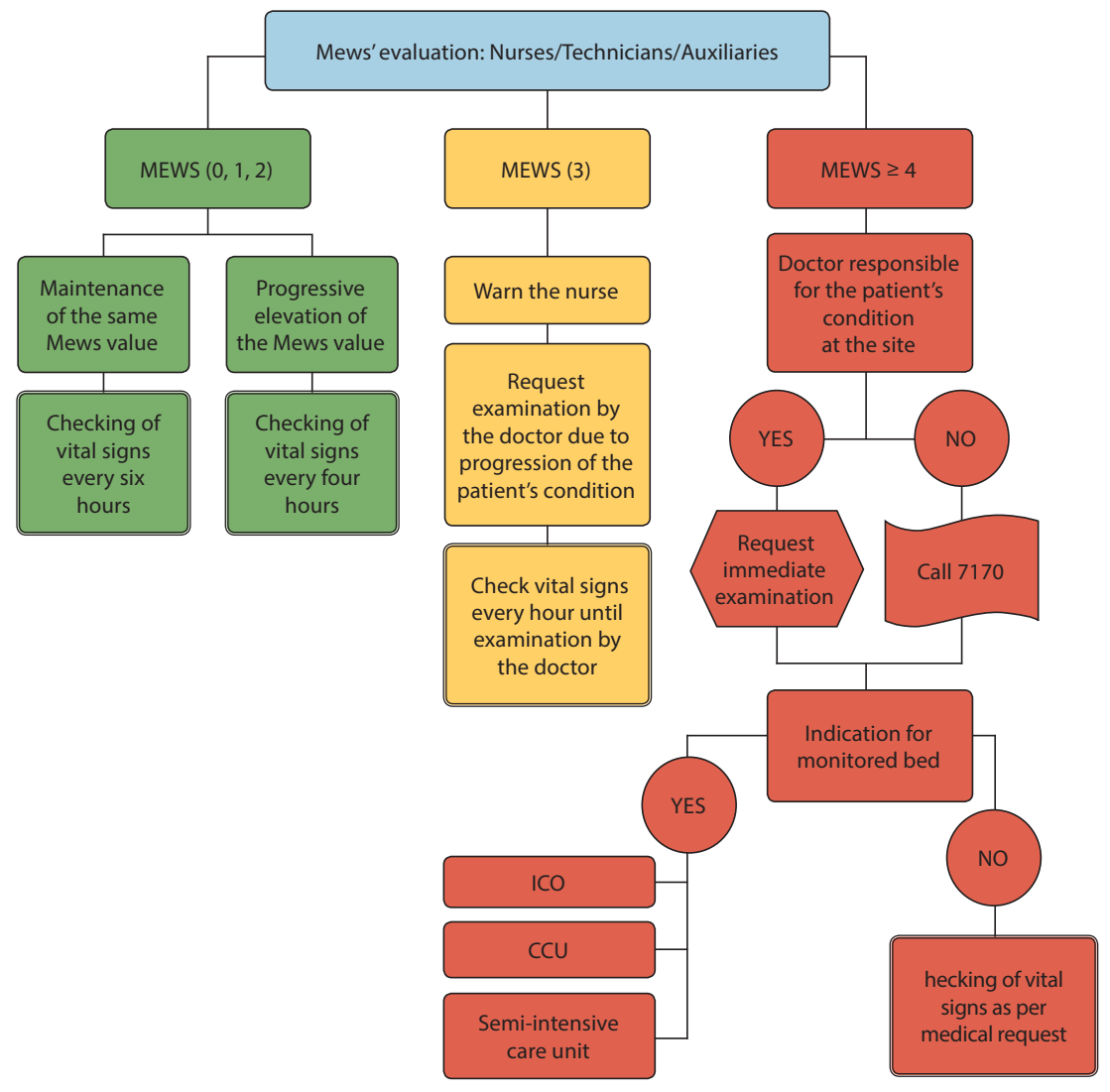

Source: HCFMRP, 2016. Note: modified early warning score (Mews).

Figure 4 - Flowchart of conducts according to the Mews value found during the assessment of vital signs. Ribeirão Preto, São Paulo, Brazil, 2016.

actions, interpersonal communication, equipment/material, records and follow-up. Therefore, the incorporation of scores such as Mews for the integration of all care practices in the treatment of hospitalized patients and continuous follow-up and adaptations according to the response observed by the care team is justified.

\section{Study limitations}

The first limitation of this study is the fact of it having been carried out in a single health care unit; thus, the results could be different for similar researches conducted in other units within the same hospital. However, on the other hand, as it is a general nursing ward of an emergency hospital, this unit offers a very diverse clinical profile of patients, which, in a way, would allow the extrapolation of these results to several other health care areas.

The second limitation is related to the resistance and barriers to the use of the score identified in this work, highlighting the difficulties associated with the level of training, work overload and resistance to change on the part of some professionals. These factors may be subject to change, as the promotion of the score's application by the nursing staff can be achieved from the moment it is inserted within a flowchart of conducts that will standardize the communication between the different professionals watching the patient, thus facilitating the performance of the nursing team, especially of younger and less experienced professionals.

The third limitation is due to the shortage of Brazilian publications on the theme, there being only one article published by Tavares et al. ${ }^{(16)}$ using Mews in the evaluation of patients admitted to the ICU, which compares it to other scores and prognostic indices, and thus has no evidence of comparability with our study. In this sense, we had to discuss the data based on the international literature.

The fourth limitation concerns our investigation having shown that this score properly measures the number of events (death, unexpected CRA and transfer to monitored bed), but not whether its systematic application within a flowchart of conducts would impact the reduction of these severe outcomes. Regarding this fact, there is still a lot of controversy in the literature. This was not the initial purpose of this investigation, but our data will allow future comparisons in relation to the number of severe events observed in this nursing ward after the proper implementation of the use of the score within a flowchart including the rapid response team.

\section{Contributions to the fields of nursing, health or public policy}

This study has a practical framework and clear applicability in the identification of patients at risk of death, unexpected CRA and transfer to monitored bed due to severe deterioration of their vital signs, using a score that is easy to be applied, handled and interpreted not only by nursing professionals, but also by the multidisciplinary team. In this sense, Mews is a support tool to be used by nurses to prevent the patients' clinical worsening and facilitate the management of care practices more widely and systematically. Mews is also a patient screening tool to be used by the clinical pharmacy, allowing the expedition of the screening and pharmacotherapeutic evaluation of patients with higher scores.

In terms of health and public health, it is a score that reduces hospital mortality, improves the quality of health care and functions as an organizational management tool. Hospitals would only benefit from the incorporation of a lightweight technology with positive impacts in terms of patient survival and mortality reduction.

\section{CONCLUSION}

Mews properly measured the occurrence of severe events such as unexpected death, cardiopulmonary arrest and transfer to the ICU in patients hospitalized in a general nursing ward of a Brazilian public emergency hospital. A Mews value higher and equal to 4 seems to be the most appropriate cut-off point for the rapid response team's triggering in this scenario. However, it seems most appropriate that each institution carries out its own validation process, taking into account all the particularities associated with it. The impact of the use of Mews within response flowcharts to reduce severe events such as death or cardiopulmonary arrest in patients hospitalized in a general nursing ward still needs to be further analyzed. 


\section{ERRATUM}

Article"Evaluation of the performance of the modified early warning score in a Brazilian public hospital", with number of DOI: http://dx.doi.org/10.1590/0034-71672017-0537, published in the journal Revista Brasileira de Enfermagem, v72(6):1428-34, on page 1428:

Where it read:

\section{Carlos Henrique Miranda Rodrigues' ORCID: 0000-0002-4420-6401}

Montenegro SMSL, Rodrigues CHM. Evaluation of the performance of the modified early warning score in a Brazilian public hospital. Rev Bras Enferm. 2019;72(6):1428-34. doi: http://dx.doi.org/10.1590/0034-71672017-0537
Read:

\section{Carlos Henrique Miranda'}

ORCID: 0000-0002-5968-4879

Montenegro SMSL, Miranda CH. Evaluation of the performance of the modified early warning score in a Brazilian public hospital. Rev Bras Enferm. 2019;72(6):1428-34. doi: http://dx.doi.org/10.1590/0034-71672017-0537

\section{REFERENCES}

1. Subbe CP, Slater A, Menon D, Gemmell L. Validation of physiological scoring systems in the accident and emergency department. Emerg Med J. 2006;23(11):841-5. doi: 10.1136/emj.2006.035816

2. Alam N, Hobbelink EL, van Tienhoven AJ, van de Ven PM, Jansma EP, Nanayakkara PW. The impact of the use of the Early Warning Score (EWS) on patient outcomes: a systematic review. Resuscitation. 2014;85(5):587-594. doi: 10.1016/j.resuscitation.2014.01.013

3. Jones D, Mitchell I, Hillman K, Story D. Defining clinical deterioration. Resuscitation. 2013;84(8):1029-34. doi: 10.1016/j. resuscitation.2013.01.013

4. DeVita MA, Smith GB, Adam SK, Adams-Pizarro I, Buist M, Bellomo R, et al. "Identifying the hospitalized patient in crisis": a consensus conference on the afferent limb of rapid response systems. Resuscitation. 2010;81(4):375-82. doi: 10.1016/j.resuscitation.2009.12.008

5. Lee A, Bishop G, Hillman KM, Daffurn K. The medical emergency team. Anaesth Intensive Care. 1995;23(2):183-6. doi: $10.1177 / 0310057 X 9502300210$

6. van Rooijen CR, De Ruijter W, van Dam B. Evaluation of the threshold value for the Early Warning Score on general wards. Neth J Med [Internet]. 2013 [cited 2017 Jan 12];71(1):38-43. Available from: http://www.njmonline.nl/article.php?a=1264\&d=820\&i=155

7. Smith GB, Prytherch DR, Schmidt PE, Featherstone PI, Higgins B. A review, and performance evaluation, of single-parameter "track and trigger" systems. Resuscitation. 2008;79(1):11-21. doi: 10.1016/j.resuscitation.2008.05.004

8. Prytherch DR, Smith GP, Schmidt PE, Featherstone PI. ViEWS - towards a national Early Warning Score for detecting adult inpatient deterioration. Resuscitation. 2010;81(8):932-7. doi: 10.1016/j.resuscitation.2010.04.014

9. Smith ME, Chiovaro JC, O'Neil M, Kansagara D, Quiñones AR, Freeman, M et al. Early warning system scores for clinical deterioration in hospitalized patients. Ann Am Thorac Soc. 2014;11(9):1454-65. doi: 10.1513/AnnalsATS.201403-102OC

10. Ho LO, Li H, Shahidah N, Koh ZX, Sultana P, Ong MEH. Poor performance of the modified early warning score for predicting mortality in critically ill patients presenting to an emergency department. World J Emerg Med. 2013;4(4):273-8. doi: 10.5847/wjem.j.is sn.1920-8642.2013.04.005

11. Wheeler I, Price C, Sitch A, Banda P, Kellett J, Nyirenda M, et al. Early warning scores generated in developed healthcare settings are not sufficient at predicting early mortality in Blantyre, Malawi: a prospective cohort study. PLoS One. 2013;8(3):e59830. doi: 10.1371/journal. pone. 0059830

12. Adam SK, Odel M, Welch J. Rapid assessment of the acutely ill patient. Oxford: Wiley-Blackwell; 2010.

13. Correia N, Rodrigues RP, Sá M, Dias P, Lopes L, Paiva A. Improving recognition of patients at risk in a Portuguese general hospital: results from a preliminary study on the early warning score. Int J Emerg Med. 2014;7:22. doi: 10.1186/s12245-014-0022-7

14. Leandro L. Tradução, validação e aplicação dos sistemas de pontuação de alerta precoce "ViEWS" e "NEWS" em Portugal [Dissertação] [Internet]. Lisboa: Escola Superior de Tecnologia da Saúde de Lisboa/Instituto Politécnico de Lisboa; Escola Superior de Saúde da Universidade do Algarve; 2014 [cited 2017 Jan 12]. Available from: http://repositorio.ipl.pt/handle/10400.21/4230

15. Albino AP, Jacinto V. Implementação da escala de alerta precoce EWS (Detecção do doente crítico). Centro Hospitalar do Barlavento Algarvio [Internet]. 2010 [cited 2017 jan. 12]. Available from: https://docplayer.com.br/3574447-Implementacao-da-escala-de-alertaprecoce-ews-deteccao-do-doente-critico.html.

16. Tavares RCF, Vieira AS, Uchoa LV, Peixoto Jr AA, Meneses FA. Validation of an Early Warning Score in Pre-Intensive Care Unit. RBTI [Internet]. 2008 [cited 2019 Mar 7];20(2):124-7. Available from: http://www.scielo.br/pdf/rbti/v20n2/en_02.pdf. 